\title{
The Efficiency of Distributed and Centralized Power System Integration
}

\author{
Felix Byk $^{1 *}$, Yana Frolova ${ }^{1 *}$, and Ludmila Myshkina ${ }^{1}$ \\ ${ }^{1}$ Novosibirsk state technical university, Karla Marksa, 20, Novosibirsk, Russia.
}

\begin{abstract}
The existing centralized power supply system has the alternative due to distributed generation. By certain conditions distributed cogeneration allows to increase the reliability and quality of power supply and to reduce the cost of electricity for consumers. Therefore, a lot of energy-intensive consumers switched to their own power supply systems, as it turned out to be a competitive technical solution. The total gasification of the country's regions and the presence of domestic manufacturers of gas turbine and gas piston power plants accelerated this process. Nowadays local power systems are emerging with cogeneration plants are the main source of heat and electricity there. The feasibility justification of the kind and type of generation is determined by many factors, including circuit-mode parameters in the local power system and adjacent network. Local power systems based on the principles of self-balance are proposed to name as energy cells. The integration of energy cells with regional power system increases the technical and economic effectiveness of power supply system for consumers. The proposed power systems transition leads to certain systemic effects. Received effects are depending on functions of distributed generation. This paper explores the impact of scheme and mode factor on the technical effects.
\end{abstract}

\section{Challenges affecting the emergence of distributed generation in Russia}

The existing Russian Unified Power System (UPS) has exhausted its efficiency resource.

Contradictions between the concentrated production and distributed electricity consumption have appeared.120.3 GW of generating capacity is installed at 53 large power plants [1]. It equals for less than $15 \%$ of the total number of power plants. These plants cover more than $80 \%$ of load in the UPS area in 2018 [3]. In addition, the construction of new large power plants is continuing today.

The decrease of large energy-intensive industries quantity of increase of distributed load of small and medium-sized businesses are occurred by the rising concentration of power production. The part of industry in power consumption in Moscow was $67 \%$ in 1985. It decreased to $30 \%$ in 2005 [2]. The main consumption volume consists of non-productive sphere in many regions.

Almost everywhere we can see increasing proportion of power consumption by the population and nonindustrial consumers. Increasing quantity of nonindustrial consumers (public services enterprises, office buildings, shopping centers, banks, hotels, etc.) are not supported by new construction and reconstruction of distribution networks. This is the reason of reducing the availability of connecting consumers to the regional power supply system.

There is a dissonance between the high rates of growth in the cost of electricity and the low rates of growth in the number of consumers and the volume of electricity consumption. That reduces the competitiveness of the national economy.

Reliability level and power supply quality also doesn't satisfy consumers. Medium frequency and time of interruption of power supply in the regions are higher than they are in other countries. It's called by the technical condition and load mode of network equipment.

The growing deterioration of network equipment forces the network companies to search for new ways to generate revenue for the implementation of measures for maintenance and repair, and re-equipment and reconstruction. An example is the requirement of PJSC "Rosseti" to introduce payment for network reservation for consumers. Another example is the reduction of requirements defining the quality of power supply to consumers. GOST 32144-2013 sets a lower rate for the duration of the failure to 1 minute [4]. In this way, changes were made to GOST 13109-97. The limited duration of the failure was set to 30 seconds according to this GOST.

All of this forced consumers to look for ways to reduce dependence on centralized power supply systems. As result the self-power supply systems (SPSS) appeared. SPSS usually are not integrated into the regional power systems. Multi-unit power plants related to distributed (from 1 to $25 \mathrm{MW}$ ) generation (DG) are often used as sources at SPSS. These units are using non-renewable (traditional DG) and renewable energy 
(alternative DG) sources.

Customers are forced to set their own reserve power sources due to the problems with power supply reliability. Diesel or gas generators are usually used. Recently, an power storage system (PSS) has been used as a reserve. Except the reserve function, the ability to align load curve is an advantage of PSS. They are effectively used not only for "cutting" peak load (discharge mode) but also for "filling up" the load curve (charging mode).

It should be noticed that the situation with energy resources available in the regions has changed dramatically since 2001. The implementation of the "Gasification Program for the Regions of the Russian Federation" [5] allowed to carry out the gasification of 66 regions. Average level of gasification is reached to $72 \%$ in 2018. Wherein in the Central Federal District gasification level has reached the $80 \%$, in the Southern Federal District - $86 \%$, in the Volga region- $86 \%$, the Caucasus is $91 \%$. Prospects of gasification at the Siberian regions are associated with the construction of a new gas transmission system "Power of Siberia" and the realization of Eastern gas program at the Far East.

Advantageous conditions have appeared for cogeneration gas piston (GPU) and gas turbine (GTU) units of domestic and foreign production of various capacities due to the change in the regions' fuel landscape. The creation of local energy systems based on them can be a result of their usage at SPSS.

It is obvious that the energy efficiency of multi-unit cogeneration power plants is determined by the presence and ratio of consumers of thermal and electrical energy. Obviously, the products of cogeneration plants are competitive with sources that produce one type of energy. [6]. That's why the state policy provides the reconstruction of heating plants with their compulsory transfer to the cogeneration mode. [7]. This stimulates the emergence of local power systems based on various types of distributed cogeneration.

With the high probability new power transition in the development of the national power system should be expected. This is the emergence of local power systems and their integration with regional power supply systems. Integration will be accompanied by significant systemic technical and economic effects such as increasing reliability and quality of power supply, increasing the filling rate and the unevenness of load curve, reducing the cost of the regional electric network companies' (RENC) development and etc.

However, the size of the effects is largely determined by the circuit-mode factors. These issues are currently not explored and require relevant research. Pilot projects of the local power systems integration are known. Their connection to the regional power supply system's networks differs from the terms of accession of the DG.

\section{Functions and effects of the local power systems integration}

The local and regional power supply systems integration allows DG to carry out new functions except the function of being the main energy source. Obviously, the quantity of the effects extracted during integration depends on the number and amount of functions performed. It is proposed to identify three additional functions and corresponding operating modes of DG.

Mode with "zero" active power flow between local and regional power supply system. The main effect from performing a specified function is improvement of the power supply reliability by the mutual reservation. In [8] was shown the reducing of time and frequency of interruptions of electricity consumers in both local and regional power systems during integration.

Mode with peak load on the generating capacity of the local power supply system and output of excess power to the regional power grid. Performance of this function leads to a reduction of technical requirements for the re-equipment and reconstruction of the regional power supply system networks. Energy efficiency of electricity supply to consumers increases by the increasing of factor of useful fuel consumption (FUFC). Increase of the use factor of a power (UFP) is accompanied by a decreasing load of external network.

Using of generating units of the local power system in service of demand response. The loading of free and reserve DG capacities and their transfer as an adjusting resource to the aggregator ensure the reduction of peak loads and increase in irregularity and density rates of load curves attached to the power supply center. The durability of network facilities can be increased as the point of reliability.

It should be noticed that the connection of local power supply systems is accompanied by increasing power supply quality. It's caused by using automatic voltage regulator (AVR) for multi-agent voltage regulation $[9,10]$. Maintaining the voltage level in the nodes increases the stability of the motor load and allows to optimize the loss of active power in the external networks.

The aim of this work is to assess the effect of the circuit-mode factor on the system effects of the integration of the local power system.

Calculations of electric modes were performed for various DG functions to achieve this aim. The calculations let to assess the possibility of their implementation, to identify the limitations from the standpoint of maintaining mode parameters. The possibility of expanding the local power system by increasing the installed DG capacity is being considered at the same time.

The scientific significance lies in the development of a program of numerical experiments for solving the tasks. Calculations on the example of a specific local power system and analysis of the results indicate the practical utility of research.

\section{The concept of local power supply systems}


The development called "Active Power Engineering Complex" (APEC) can be marked as one of the concepts of creating local power supply systems [11]. Active Power Engineering Complex is a set of electrically connected generating facilities, power storage systems, network facilities and power-receiving devices of electricity consumers, united by a single system to maintain the balance of production and consumption and connected with the external system at one point with controlled (managed) parameters. Only industrial manufacturers and large commercial centers are considered in APEC.

The main options of the existing concept of APEC:

- only one of the APEC facilities has a connection point to the networks of the RENC;

- all APEC facilities are connected through network facilities that are not owned by RENC;

- regulation of the production and consumption of electricity (power) in APEC is managed by intellectual connections of active power engineering complex;

- a shortage of power and energy may be in APEC and it's covered by the transfer from the external network.

There is a different concept of power engineering development based on the integration of energy cells. Energy Cell (EnC) is a local power system (technical system) based on the principle of self-balance and is formed by a distribution network with $0.4-10 \mathrm{kV}$ voltage. EnC unites generating sources with various consumer groups. Power supply at EnC is carried out in compliance with the technical standards for reliability and quality of power supply.

The principle of self-balance involves the construction of a self-sufficient power system. The EnC should be able to operate in island mode with saving the required level of quality and reliability of the power supply to its consumers.

Energy Cells is vertically integrated power system with its own control system, which ensures its functioning in normal, emergency and post-accident modes. Its area is restricted by the $10 \mathrm{kV}$ network length. The essential difference of the energy cell is to provide consumers with not only electricity, but also thermal energy. It means improving of energy efficiency.

\section{The program of mode parameters' calculation for integration}

To identify the impact of mode parameters on the integration process a program of numerical experiments was offered. For the analysis of power and energy losses and their changes following modes were calculated:

1. without connection energy cells to the external network (isolated mode);

2. connecting the energy cell to external network with "zero" active power flow.

3. peak load of DG unit with the overage power transfer to the external network.

4. using generating unit capacity of DG for demand response.
The voltage deviations in the nodes for compliance with [4] and the current load of the network are monitored while the functions analysis. The standard deviations of voltage at the nodes of the network, the total power losses in the EnC and the external network are taken to quantify the effects.

Modes 3 and 4 lead to load changes in power supply center, where EnC is connected. Changing of losses in $110 \mathrm{kV}$ network is proportional to the power supply center load. Integral indicators of the change in energy losses were used over the daily time interval in the corresponding network areas for the comprehensive analyzis. Simplified calculation of energy losses made by the equations:

$$
\begin{gathered}
\Delta W=\tau \cdot \Delta P, \\
\tau=\left(0,124+\frac{T_{\max }}{10000}\right)^{2} 24
\end{gathered}
$$

$\tau$ - the time of greatest loss, hours;

$T_{\max }=6000$ hours, for areas with predominance of industrial load and $T_{\max }=4500$ hours for areas with predominantly domestic load, converted to daily time interval according to [12].

To assess the changes of energy losses in networks the expression was used:

$$
\partial W_{\Sigma}=\left(\Delta W_{0}-\Delta W_{f}\right)+\partial W_{110},
$$

$\partial W_{\Sigma}$ - Systemic effect changes of energy losses in networks, MW·h;

$\Delta W_{0}$ - Network energy loss in $10 \mathrm{kV}$ in island mode of $\mathrm{EnC}, \mathrm{MW} \cdot \mathrm{h}$;

$\Delta W_{f}$ - Energy losses in the explored circuit during integration and performance of specified functions, $\mathrm{MW} \cdot \mathrm{h}$;

$\partial W_{110}$ - Loss changing in $110 \mathrm{kV}$ network in parallel mode of EnC and the fulfill of the specified functions, $\mathrm{MW} \cdot \mathrm{h}$.

A two-stage load curve was adopted for modeling the peak load mode. And the maximum power $\left(P_{\max }\right)$ there is equal to the maximum power of $\mathrm{DG}$, minimum plant power $\left(P_{\text {min }}\right)$ - minimum power at load curve of EnC. The duration of the maximum power load is determined by the time of demand response (t). According to [13], this time equals 4 or 2 hour per day.

$$
\Delta W_{f}=\left(\Delta P_{E n C_{-} \max }+\Delta P_{\text {grid_max }}\right) \cdot t+\Delta P_{\min } \cdot(24-t),
$$

$\mathrm{t}$ - the number of hours per day with the possibility of providing resources for demand response management, h.

$\Delta P_{E n C_{-} \max }-$ Power losses in the EnC in peak mode, $\mathrm{MW}$;

$\Delta P_{\text {grid_max }}-$ Power losses in the external network in peak mode, MW;

$\Delta P_{\text {min }}$ - Total losses in the area (EnC and external network) in the minimum mode, MW. 


\section{Analysis of the admissibility of performed functions during integration of energy cells}

A power system with mostly municipal load was chosen as example of energy cell. EnC load consists of primarily domestic consumption $(70 \%)$ with the low level of nonproductive manufacturers related to services $(30 \%)$. The peak load of the $\mathrm{EnC}$ is $3 \mathrm{MW}$. Generation capacity consists of three generators of $2 \mathrm{MW}$.

The ratio of residential and industrial consumers is $40 \%$ and $60 \%$ for the area of the external network, which $\mathrm{EnC}$ is connected. The peak load there is $6 \mathrm{MW}$.

There are lines of external network connection with busbars of $110 / 10 \mathrm{kV}$ power supply center (lines 17-19 and 18-20) in section 1 . Section 2 is formed by lines 1-3 and 2-4, which allow to determine production of power plants and the main power sources of EnC. Section 3 is formed by the transmission lines connection $\mathrm{EnC}$ and external network (lines3-19, 4-2).

RastrWin was used for the calculation of electric modes, in accordance with the program of calculation.

The calculation results are shown in table 1 . Calculation in isolated mode has shown the consistency of energy cells, working on the principle of selfbalances.

Connecting EnC for parallel work with the power system with "zero" active power flow decreases voltage standard deviation in nodes of both local and regional power supply systems. It indicates an increase in the quality of power supply to consumers due to the appearance of a source of reactive power in the area. This is a positive addition to the mutual voltage reservation in case of disconnection of lines at section 1 or 2.

There are no operating restrictions in peak load mode of DG, providing maximum FUFC and UFP. Power supply quality of $10 \mathrm{kV}$ nodes increases in comparison with "zero" active power flow mode for both EnC and external network. Some increase of power losses is caused by increase in the line load of section 3 . However, the total energy loss reduces through the active power flows redistribution in $110 \mathrm{kV}$ network. It lets to say about energy-saving effect due to operation of specified function.

Duration of using DG for demand response was modeled for 4 hour per day. The absence of regime restrictions on the performance of this function is revealed as a result of mode calculation.

Basing on the obtained results it can be concluded that there are no mode restrictions for integration. The execution of the analyzed functions is valid for the considered example.

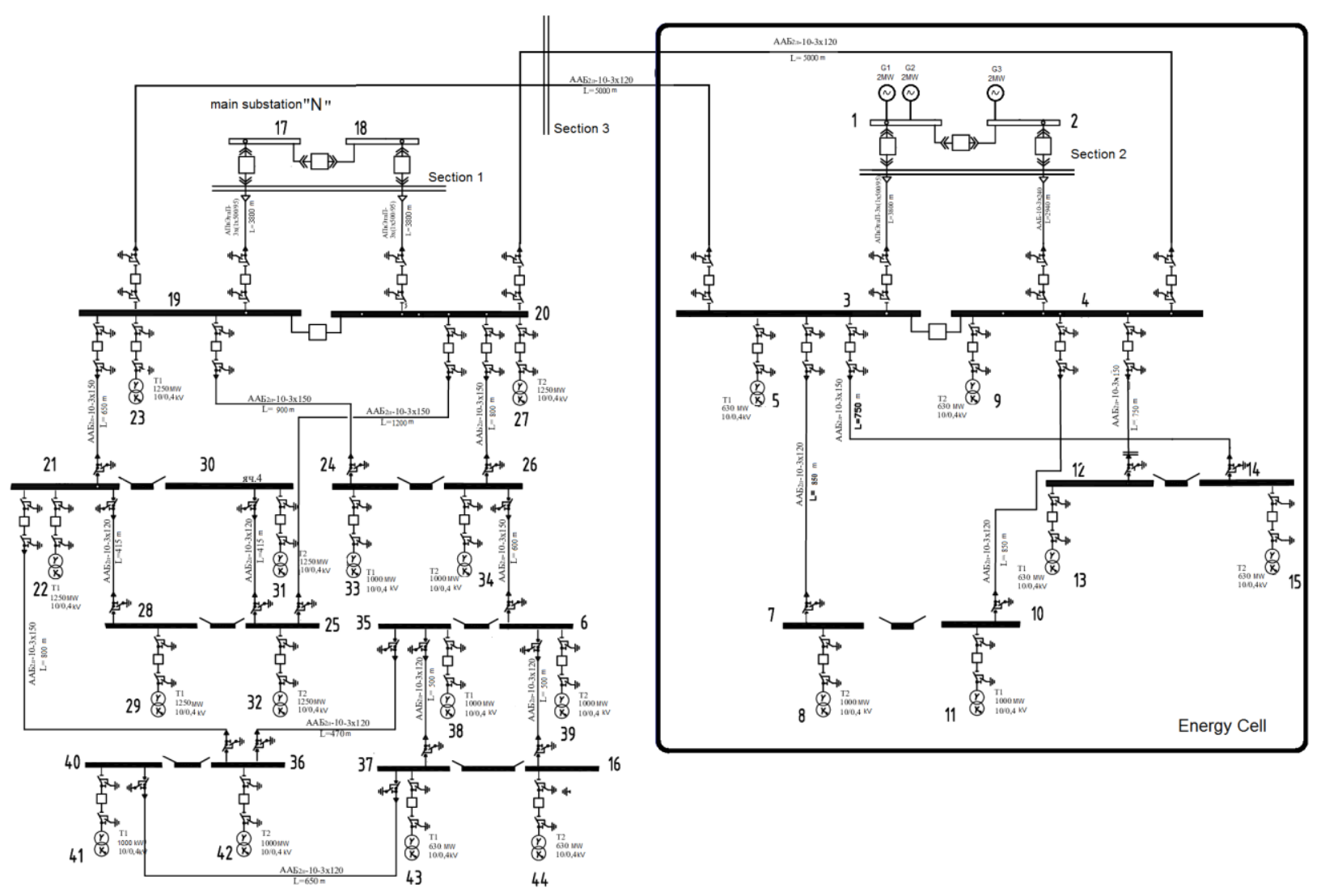

Fig. 1. Computational scheme of EnC and external network. 
Table 1 results of calculation at peak mode

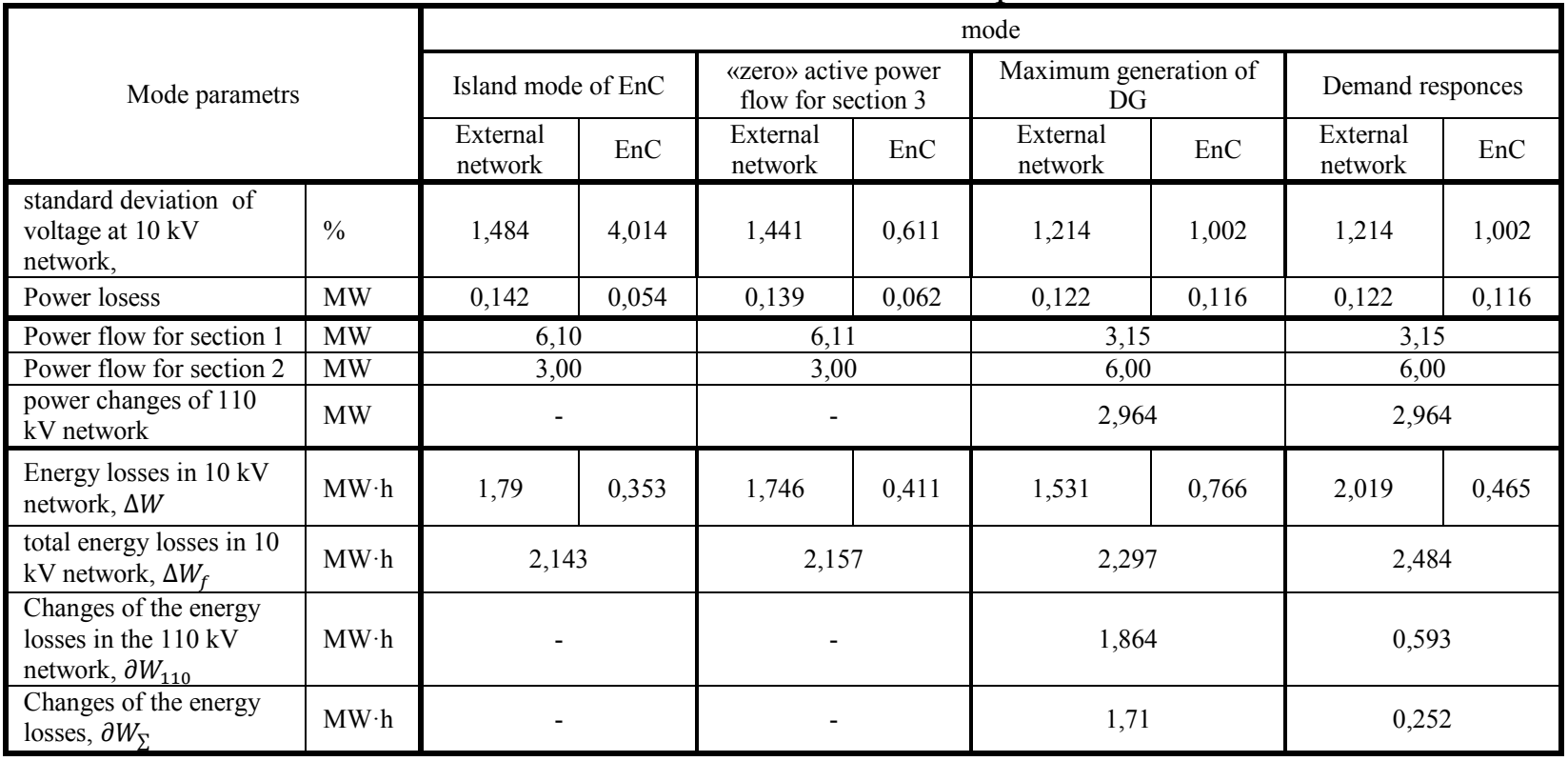

The greatest efficiency from the standpoint of increasing energy efficiency, energy saving, quality and reliability of power supply is the mode of DG peak load. This mode is considered to be the basis for technical solutions of energy cells integration with the regional power supply system.

\section{Analysis of expanding energy cells posibility}

Let's consider the option of energy cells expanding due to inclusion of new consumers, which power supply iss carried out by the power supply center $« \mathrm{~N} » 110 / 10 \mathrm{kV}$ (Figure 1).

Total consumers' load is $9 \mathrm{MW}$. Therefore, to cover the load with ensuring the required level of reliability of power supply, it's necessary to increase the installed capacity of DG to $12 \mathrm{MW}$. That is 3 additional $2 \mathrm{MW}$ units. The modes were calculated for the existing model of EnC according to the proposed program of numerical experiments. Results are presented in table 2 .

It was revealed, that the expansion of DG up to 12 MW is not enough for operating in island mode. Limitations of the adjustment capabilities of units' AVR don't allow to maintain the voltage level in the load nodes during the operation in island mode. It is necessary to install the additional generation unit. DG power has to be increased up to $14 \mathrm{MW}$. Another way to eliminate the reactive power shortage is to connect to the network. That turns EnC into APEC. In case of failure of the transmission line at section 1 the quality of the power supply will be reduced or the industrial consumers will be disconnected.

Consequently, an important point of designing an EnC is a demand response management. Also it's necessary to take into account the requirements of maintaining mode parameters.

Table 2 Results of calculation at maximum output DG power increase up to $12 \mathrm{MW}$.

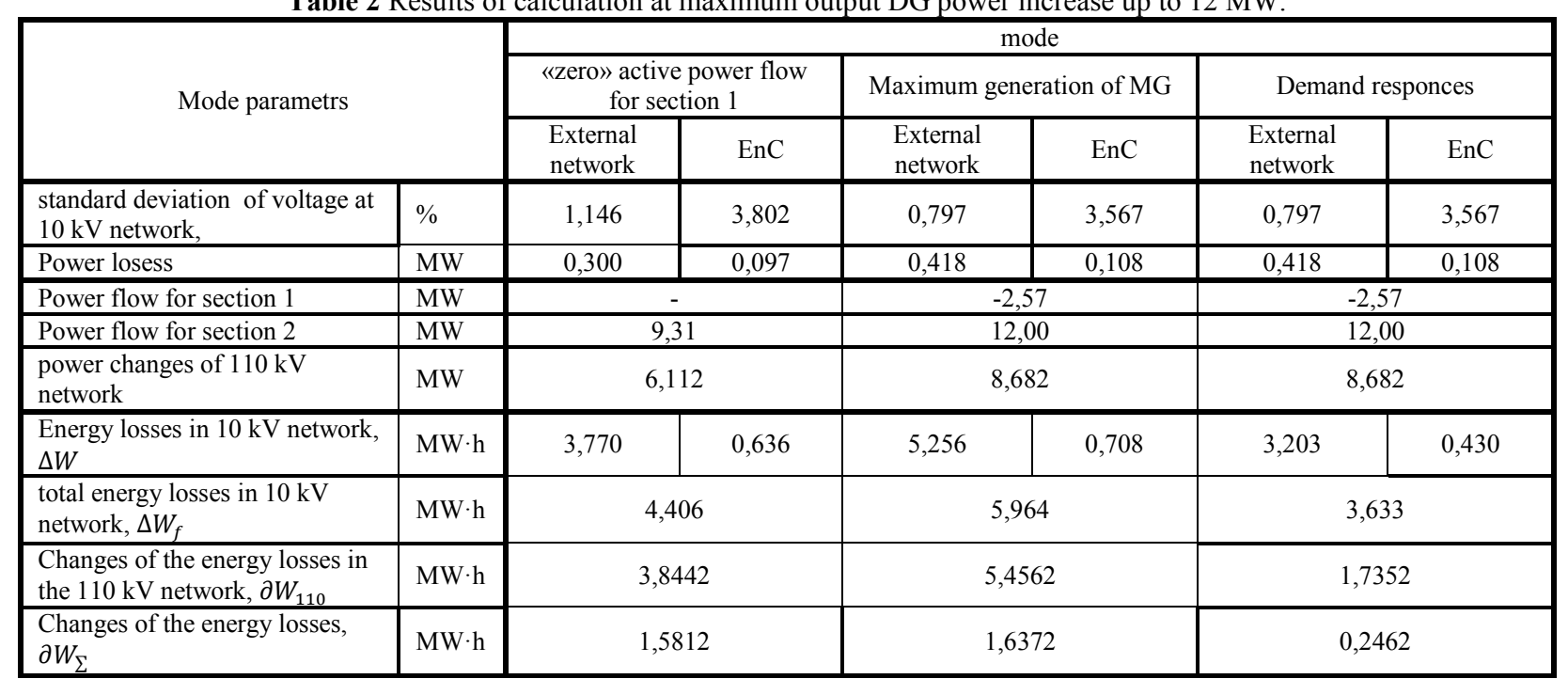

\footnotetext{
${ }^{2}-$ comparison with energy cell's island mode with $6 \mathrm{MW}$ of installed power.
} 
It should be noted that the increase of installed capacity MG up to $12 \mathrm{MW}$ doesn't lead to increase of energy efficiency. The decrease in energy loss is comparable with the values before the expansion of the EnC. The calculations presented in this paper were carried out in the absence of restrictions on reactive power and maintaining the rated voltage on the power supply center's busbars. However, there are areas in the power system where problems with maintaining $10 \mathrm{kV}$ voltage on the power supply center are more acute. These are dead-end 110/10 kV substations, which are provided with power by long $110 \mathrm{kV}$ power transmission lines. The size of energy saving may be more significant in that case.

\section{Conclusion}

1. It should be expected that the local power systems will be designed and emerged as self-balance power systems for small and medium-sized consumers.

2. Total regions' gasification and the need for reconstruction of small and medium-sized heating plants with their reconstruction to cogeneration operation mode stimulates the appearance of distributed cogeneration. It stimulates the emergence of local power systems based on them.

3. At the first stage, local power systems will be forced to work in an isolated (island) mode. It causes the emergence of energy cells. However, in order to improve the efficiency of domestic power engineering it will be necessary to integrate them with regional power supply systems.

4. The main difference of the energy cell is its work on the principles of self-balance in electricity and thermal energy. The results indicate the need of carrying out the demand response function in case of designing and expanding of energy cells with taking into account the requirements of maintaining the standard values of mode parameters.

5. It is obvious that the integration of energy cells will be accompanied by various systemic effects due to performing new functions by distributed generation. The most significant ones include the effects of mutual voltage reservation, raising the use factor of a ppower and factor of useful fuel consumption, increase of the irregularity rates and filling (density) of load graph.

6. The program of numerical experiments was proposed. Technical validity of the execution of these functions in various circuit-mode conditions was shown. Priorities from the point of energy saving were identified. It's recommended to consider the peak load of distributed generation as the main regime for technical solutions of integration of local to regional power systems.

7. The reliability of the received results is confirmed by the reduced voltage standard deviation in the network nodes $10 \mathrm{kV}$ as the effect of the multi-agent voltage regulation due to attraction of automatic voltage regulator. Further research in this area involves the exploring the applying functions' effectiveness from the point of reducing the voltage waveform distortion caused by harmonic components of the current consumed by the non-linear load, reducing asymmetry of currents and voltages and etc.

This work was financially supported by the Novosibirsk State Technical University (C19-26 project).

\section{References}

1. The list of Russian Federation power plants. Total installed capacity of power generation [Online]. Available: https://electricalnet.ru/blog/perechenelektrostantsii-rf-summarnaya-ustanovlennaya-

moschnost-elektrogeneratsii, (Accessed on: Apr. 12, 2019)

2. B.I. Makokliuev Energy of Unified Grid, 4, 56 (2012)

3. Report on the functioning of the UES of Russia in 2018 [Online]. Available: https://soups.ru/fileadmin/files/company/reports/disclosure/2019/ ups_rep2018.pdf, (Accessed on: Apr. 10, 2019).

4. Electric energy. Electromagnetic compatibility of technical equipment. Power quality limits in the public power supply systems, GOST 32144-2013, 2013

5. Implementation of the Gasification Program for the Regions of the Russian Federation PJSC Gazprom [Online]. Available: http://www.gazprom.ru/about/production/gasification, (Accessed on: Apr. 15, 2019.)

6. V.M. Batenin, V.V. Bushuev, N.I. Voropai Innovative electric power industry - 21 (Irkutsk, 2017)

7. Federal Law (2010, Jul. 27, as amended on 2018 Jul. 29), N. 190-FZ, On heat supply.

8. L.S. Myshkina Power engineering: research, equipment, technology, 19, 23 (2017)

9. E. N. Gezha, V. E. Glazyrin, G. V. Glazyrin, A. I. Marchenko, R. Iu. Semendiaev, A. G. Fishov Releishchik 2, 24 (2018)

10. N.A. Kardzhaubaev, A.G. Fishov Proceedings of ISTU 22183 (2018)

11. K.A. Datsko Electric power news, 1, 1 (2018)

12. Handbook for the design of electrical networks, 4th ed. ENAS, Moscow, Russia, 2012

13. Government of the Russian Federation. (2019, Mar. 20), N. 287, On Amendments to Certain Acts of the Government of the Russian Federation on meeting the needs of the authorities in ensuring the unified energy system of Russia, as well as improving the pricedependent mechanism for reducing energy consumption and providing energy supply services system reliability 